\title{
Misplaced ("Missing") Intrauterine Contraceptive Device Among Clients at a Rural Tertiary Hospital in South Western Nigeria
}

\author{
Adeniyi Augustine Adebayo, 2, *, Adebisi Timothy Olumide², Okere Raymond Akujuobi ${ }^{1,2}$, \\ Adebara Idowu Oluseyi ${ }^{1,2}$, Bakare Adewumi ${ }^{1,2}$, Adeyemo Olabisi Timoty ${ }^{1,2}$, \\ Busari Adesola Olusegun ${ }^{3}$, Achebe Chijioke Cosmas ${ }^{4}$, Amerijoye Adewale ${ }^{2}$ \\ ${ }^{1}$ Department of Obstetrics and Gynaecology, Afe Babalola University, Ado Ekiti, Nigeria \\ ${ }^{2}$ Department of Obstetrics and Gynaecology, Federal Teaching Hospital, Ido Ekiti, Nigeria \\ ${ }^{3}$ Department of Medicine, Afe Babalola University, Ado Ekiti, Nigeria \\ ${ }^{4}$ Department of Radiology, Afe Babalola University, Ado Ekiti, Nigeria
}

Email address:

bayoadeniyis@gmail.com (A. A. Adebayo)

${ }^{*}$ Corresponding author

\section{To cite this article:}

Adeniyi Augustine Adebayo, Adebisi Timothy Olumide, Okere Raymond Akujuobi, Adebara Idowu Oluseyi, Bakare Adewumi, Adeyemo Timothy Olabisi, Busari Adesola Olusegun, Achebe Chijioke Cosmas, Amerijoye Adewal. Misplaced ("Missing") Intrauterine Contraceptive Device Among Clients at a Rural Tertiary Hospital in South Western Nigeria. Journal of Gynecology and Obstetrics.

Vol. 7, No. 2, 2019, pp. 51-55. doi: 10.11648/j.jgo.20190702.15

Received: March 5, 2019; Accepted: April 26, 2019; Published: May 20, 2019

\begin{abstract}
Background: Misplacement is one of the complications reported with intrauterine contraceptive devices (IUCDs) as a form of contraception. Objective: To study the methods of diagnosis and the mode of management of misplaced IUCDs at the Federal Teaching Hospital, Ido-Ekiti. Methods: This was a retrospective review of records of all clients who presented with complaints of missing IUCD over a 5 year period, from 1st January 2011 to $31^{\text {st }}$ December 2015. Results: A total of 527 clients were seen at the family planning unit within the period under review. Three hundred and one (301) clients used IUCD, giving a prevalence of $57.1 \%$ of total contraceptive use. Of these, 12 IUCDs were reported misplaced, giving the incidence of misplaced IUCDs as 4\%. The peak age of the clients reporting misplaced IUCD was 31-40 years. IUCDs insertion during puerperium was seen in 33.4\% while most (41.6\%) had their IUCD insertion more than 12 months following last childbirth. When considering IUCD insertion in relation to abortion and menses, most (50\%) had insertion during menstrual period, 25\% had insertion just before the onset of the next menses, postabortal insertion was seen in $16.7 \%$ while one $(8.3 \%)$ could not ascertained the event that preceded the insertion of IUCD. Inability to feel the thread was the commonest presenting complaint in $6(50 \%)$. Most of the clients with misplaced IUCD had the device inserted at the primary health centre (41.6\%) and private hospitals (33.4\%). Pelvic examination with uterine sound and abdominal ultrasound were the diagnostic methods commonly used. Most clients (83.3\%) missed their IUCDs within the first twelve months of use. Retrieval hook was used for removal in $91.7 \%$ of the cases. One $(8.3 \%)$ had exploratory laparotomy to recover the missing IUCD. Conclusion: Intrauterine devices should be inserted after proper case selection by properly trained medical personnel in both primary and tertiary centres in order to reduce reported cases of missing IUCDs.
\end{abstract}

Keywords: Intrauterine Contraceptive Device, Misplacement, Diagnosis, Management

\section{Introduction}

Intrauterine contraceptive device is a long acting reversible contraceptive. It is an acceptable, common convenient, effective and relatively safe method of contraception with an estimated 127 million users of IUCDs worldwide. The use of IUCDs is disproportionally higher in developing countries $(14.5 \%)$ compared to developed countries $(7.9 \%)$. [1, 2] 
Altogether, $13.6 \%$ of couples around the world have selected IUCDs for birth control. [2] In Nigeria, the level of acceptance ranges from $39.7 \%-64 \%$ [3] with a failure rate of $1-2 \%$ each year has been reported worldwide. [2, 4] The IUCDs produce both morphological and biochemical changes in the reproductive tract by inducing inflammatory response in the endometrium, with associated increase in the levels of macrophages, and other inflammatory agents in the uterine and the tubal fluids. [5, 6]. The major risks reported in association with use of IUCDs include ectopic pregnancy, spontaneous abortion, uterine perforation and expulsion. [2, 5] Missing or misplaced IUCD is one of the setbacks associated with the use of the device. [7] Adewale et al reported an incidence of $1.4 \%$ of missing IUCD in Bida . [8] It should be noted that a missing IUCD string does not necessarily indicate perforation since it may occur when the device has been expelled unnoticed, rotation of the device within the uterine cavity, separation of the tail from the device, or rotation of string into cervical canal. [9] It has also been suggested that complete extrusion of IUCD through the myometrium may be assisted by spontaneous uterine contraction and hydrostatic negative pressure differences between the low intraperitoneal pressure and relatively higher intrauterine pressure. [10] The extruded IUCD may further migrate into the peritoneal cavity. Bowel and bladder perforations have been reported following uterine perforation due to misplaced IUCDs. [11] The risk factors for misplaced IUCD include the time of insertion, type, size and configuration of IUCD used as well as the skill and experience of inserter. [12] Proper insertion of an IUCD is important since it can affect effectiveness and acceptability of the method. [13] Expulsion rate are highest in the first year especially the first three months after insertion. [11] The expulsion is also increased after early postpartum period or following caesarean section but not after first trimester abortion. [14] The different diagnostic methods used in detecting missing IUCDs include pelvic examination with uterine sound, abdomino-pelvic ultrasound alone, abdominopelvic ultrasound complimented with hysterosalpingography (HSG), plain abdominal x-ray, HSG, laparoscopy, minilaparotomy and laparotomy. [15] In some cases, there will be no associated symptoms and suspicion is made when the string cannot be identified. [7] This study was designed to document the prevalence, method of diagnosis, and management of misplaced IUCD at our centre.

\section{Materials and Methods}

The study was carried out at the Family Planning Unit of the Federal Teaching Hospital, Ido-Ekiti over a 5 year period ( $1^{\text {st }}$ January 2011 to 31 st December 2015 ). Family planning nurse practitioners were the main IUCD providers under the supervision of a Gynaecologist. The medical records of all clients who presented with misplaced IUCDs were reviewed using data extraction forms. The socio-demographic data, complaints at the time of presentation, type of previous contraception, timing of insertion, method of diagnosis, mode of retrieval and type of IUCD removed were extracted. The data were analyzed using tabulations and simple percentages.

3. RESULTS

The total number of contraceptive users at the family planning unit during the period under review was 527 . The commonest method of contraception was IUCD which accounted for $301(57.1 \%)$. Twelve (12) cases of misplaced IUCDs were diagnosed and managed giving an incidence of $4 \%$. The Socio-demographic characteristics of clients with missing IUCDs are shown in Table 1. Majority (50\%) of the clients with missing IUCDs were between 31-40 years, teenager constituted $8.3 \%$. Multiparous women constituted 8 $(66.7 \%)$ while $11(91.7 \%)$ of the clients were married. Two $(16.7 \%)$ of the clients had no form of education, others $(83.3 \%)$ have at least primary level of education.

Table 1. Socio-demographic characteristics of clients with missing IUCDs.

\begin{tabular}{lll}
\hline Variable & Frequency $(\mathbf{N}=\mathbf{1 2})$ & Percentage (\%) \\
\hline Age (Years) & & \\
$\leq 20$ & 1 & 8.3 \\
$21-30$ & 3 & 25 \\
$31-40$ & 6 & 50 \\
$41-50$ & 2 & 16.7 \\
Parity & & \\
0 & 1 & 8.3 \\
1 & 3 & 25 \\
2 & 2 & 16.7 \\
3 & 4 & 33.4 \\
4 & 1 & 8.3 \\
$\geq 5$ & 1 & 8.3 \\
Level of Education & & \\
None & 2 & 16.7 \\
Primary & 3 & 25 \\
Secondary & 5 & 41.6 \\
Tertiary & 2 & 16.7 \\
Marital Status & & 8.3 \\
Single & 1 & 91.7 \\
Married & 11 & \\
\hline
\end{tabular}

Fifty-seven percent $(57 \%)$ of clients choose intrauterine contraceptive device as the method of contraception during the study period. Other common methods are the injectables $(23 \%)$ and the subdermal implants $(10 \%)$. (Table 2$)$.

Table 2. Contraceptive Choice of clients over period of the study.

\begin{tabular}{lll}
\hline Type of Contraceptive & Frequency & Percentage \\
\hline Intrauterine Contraceptive devices & 301 & 57.1 \\
Injectables & 125 & 23.7 \\
Oral Contraceptive Pills & 27 & 5.1 \\
Barrier methods & 15 & 2.9 \\
Implants & 54 & 10.3 \\
Bilateral tubal ligation & 5 & 0.9 \\
Total Number of Clients & 527 & 100.0 \\
\hline
\end{tabular}

Three (25\%) clients had not used any form of contraceptive before the IUCDs insertion, while others had either used withdrawal, injectable, barrier or pill forms of contraceptive. One $(8.3 \%)$ had bilateral tubal ligation after retrieval of the misplaced IUCDs. Commonest place of insertion of the missing IUCDs was at the primary health Centre $5(41.6 \%)$. Other places include private hospital 4 $(33.4 \%)$, general hospital $2(16.7 \%)$ and teaching hospital 1 
(8.3\%). (Table 3).

Table 3. Place of Insertion of missing IUCDs.

\begin{tabular}{lll}
\hline Place of Insertion & Frequency (N=12) & Percentage (\%) \\
\hline Primary Health Centre & 5 & 41.6 \\
Private Hospital & 4 & 33.4 \\
General (secondary) Hospital & 2 & 16.7 \\
Teaching (tertiary) Hospital & 1 & 8.3 \\
Total & 12 & 100.0 \\
\hline
\end{tabular}

Sixty- six percent $(66.6 \%)$ of the clients with missing IUCD used IUCD for child spacing, $16.7 \%$ used it as long term contraceptive method and $16.7 \%$ did not state the reason for use as to either for child spacing or long term contraception as shown in Table 4. While there was no immediate postpartum insertion, $4(33.4 \%)$ had insertion in the puerperium while majority $6(50 \%)$ of the clients presented after 6 months of delivery for insertion. In relation to menstruation, insertion was commonest during menses $(50 \%)$ than other time of the cycle. Two clients $(16.7 \%)$ had postabortal insertion. Most (58.3\%) missed their IUCDs after 6 to 12 months of use. While most clients reported soon after missing the IUCDs, 2 clients missed their IUCDs for more than one year before presentation.

Table 4. Indication for Insertion of IUCDs.

\begin{tabular}{lll}
\hline Indication & Frequency (N) & Percentage (\%) \\
\hline Short time Child spacing & 8 & 66.6 \\
Long term Contraception & 2 & 16.7 \\
Others & 2 & 16.7 \\
Total & 12 & 100.0 \\
\hline
\end{tabular}

The missing IUCDs were still within uterine cavity in 11 $(91.7 \%)$ of the cases while one client $(8.3 \%)$ had her IUCD retrieved from the pouch of Douglas at exploratory laparotomy. None of the clients had expulsion of the IUCDs. The commonest presenting complaint was inability to feel the thread $10(83.3 \%)$ while abdominal pain was the symptom in 2 cases (16.7\%), while both symptoms occurred in 1 client. Pelvic examination with uterine sound following pelvic ultrasound $(83.3 \%)$ was the most commonly employed diagnostic method. Plain abdominal X-ray with tracer IUCDs was employed for diagnosis in only $2(16.7 \%)$ clients.

Table 5. Presentation, Diagnosis and management of the missing IUCDs.

\begin{tabular}{lll}
\hline Variable & $\begin{array}{l}\text { Frequency } \\
(\mathbf{N = 1 2 )}\end{array}$ & $\begin{array}{l}\text { Percentage } \\
(\mathbf{\%})\end{array}$ \\
\hline $\begin{array}{l}\text { Presentation } \\
\text { Inability to feel the thread }\end{array}$ & 10 & 83.3 \\
$\begin{array}{l}\text { Abdominal pain } \\
\text { Inability to feel the thread and abdominal } \\
\text { pain }\end{array}$ & 2 & 16.7 \\
$\begin{array}{l}\text { Diagnosis } \\
\text { Pelvic Ultrasound }\end{array}$ & 1 & 8.4 \\
$\begin{array}{l}\text { Plain Abdominal X-ray and tracer IUCDs } \\
\text { Treatment modality }\end{array}$ & 10 & 83.3 \\
$\begin{array}{l}\text { Cervical dilatation and Retrieval hook } \\
\text { Laparotomy }\end{array}$ & 11 & 16.7 \\
\hline
\end{tabular}

In management of missing IUCDs, dilatation and retrieval hook was successful in $91.7 \%$ of cases while 1 (8.3\%) client had exploratory laparotomy. The patient subsequently had bilateral tubal ligation during the laparotomy. None had laparoscopic removal of the missing IUCDs.

\section{Discussion}

A total of 527 clients were seen at the family planning unit within the period under review. Three hundred and one clients used IUCD, giving a prevalence of $57.1 \%$ making it the single most commonly used contraceptive at the study centre. This is similar to findings in studies by Abasiattai et al. [3] Ezegwui et al. [7] and Jimoh et al. [13] The incidence of missing IUCD within period under review was $4 \%$ which is higher than $0.25 \%$ reported by Jimoh et al in Ilorin [13] and $1.4 \%$ quoted by Adewale et al et al in Bida. [8] The higher incidence in this study may be due to the fact that most of the IUCDs were inserted at primary health centres. Majority $(75 \%)$ of clients were in $2^{\text {nd }}$ and $3^{\text {rd }}$ decade of life, which is similar to findings in Abakaliki. [5] This is not unexpected as this period represent the peak of their reproductive life. All the missing IUCDs in this study were $\mathrm{Cu} \mathrm{T} 380 \mathrm{~A}$, an higher rate of expulsion has been reported for $\mathrm{Cu} \mathrm{T} 380 \mathrm{~A}$ compared to LNG-IUS IUDs especially when inserted immediate postpartum. [16] Most (66.7\%) of the clients who presented with missing IUCDs were multiparous. This is similar to a study in Ilorin. [17] This is not unexpected as majority of the client $(83 \%)$ used the device either for child spacing or long acting contraceptive method. Most $11(91.7 \%)$ of the missing IUCDs were married. The low incidence of contraceptive use in single women may be due to cultural and religious restrictions on premarital sex and restriction on prescription of IUCDs for young and unmarried women. Three (25\%) had not used any form of contraceptive prior to their experience of missing IUCD, this may constitutes a barrier to the use of IUCDs and possibly contraception in future. The number of clients in this category is however unexpectedly lower than the $70 \%$ reported in Enugu, [7]which is more cosmopolitan and urban compared to the site of this study.

Most 11 (91.7\%) insertions were done at Primary and secondary health institutions, this emphasizes the need for the training and retraining on modern skills in inserting IUCDs at all levels of healthcare in order to reduce the incidence of missing IUCDs. Majority (41.6\%) of the insertions were done more than 1 year post-partum and usually during menses $(50 \%)$. This is in agreement with a previous study. [13] Two (16.7\%) clients had post-abortal and 4 (33.4\%) had insertions during puerperium while immediate postpartum or postplacental insertion was not reported. Postplacental insertion is being encouraged as a way of increasing the uptake of IUCDs as a method of contraception. [16] Majority (58.4\%) of missing IUCDs were reported less than 12 months after insertion, this is in agreement with published reports. $[11,13$, 14] Inability to feel the thread $(50 \%)$ was the most common complaint followed by lower abdominal pain (16.7\%), this is in contrast to report from Ilorin, in which abdominal pain was the commonest. [11] Occurrence of abdominal pain as 
symptom varied from $9.6 \%$ to $44.8 \%$ [7]. Within the peritoneal cavity copper bearing devices may excite tissue reaction which could cause pain. [18] The triad of abdominal pain, intermittent diarrhoea and fever associated with missing string may be indicative of bowel injury. [10] Lower urinary symptoms of dysuria, frequency and urgency have been reported on migration of the device into urinary bladder. [11, 19]

In this study, commonest mode of diagnosing missing IUCD was pelvic examination with uterine sounding following pelvic ultrasound, this is also the method of diagnosis in previous studies. [8, 9, 13] Ultrasonography is readily available, non-invasive with less effort, however, sonogram is not reliable if the device is surrounded by the omentum and bowel loops. [1, 21] It is effective when used early particularly in high risk patients and when the insertion is associated with severe pain probably indicating perforation. [22] In other studies, plain abdominal x-ray with a marker in the uterus was the main modality of diagnosis. This modality is said to be a reliable, popular, simple technique which does not require special skill with reported accuracy of $95.2 \%$. [7, 8] Eleven $(91.7 \%)$ of the missing IUCD were found within the uterine cavity. This was the finding in previous studies [8, 9, 23].

The first line of management was the use of retrieval hook which was successful in $91.7 \%$ of cases. This was higher than the $62.3 \%$ reported from Ilorin [13] and 65\% from Bida [8] One $(8.3 \%)$ client had laparotomy and subsequent bilateral tubal ligation, the device was found lying anterior to the bladder in the peritoneal cavity. This finding was reported in $15 \%$ of clients by Adewale et al. [8] Laparoscopy was not done for any of the patients, this may be due to the lack of skill required for the procedure . Laparoscopy is most preferred, since it is less traumatic and has less postoperative morbidity. [21, 24]The diagnostic accuracy of laparoscopy can also be enhanced by fluoroscopic guidance. [24, 25] No client had pregnancy with missing IUCD and there was no case of ectopic pregnancy, which are some of the known complications reported from previous studies. $[2,5,8]$

\section{Conclusion}

Misplaced IUCD is one of the drawbacks of use of the device which may constitute barrier to contraceptive use in future. Proper case selection of client using IUCDs will result in less reported cases. Adequate counseling will motivate the IUCDs user to present early when any complication arises. The devices should be inserted by trained medical professional as well as retraining of medical personnel on modern insertion technique.

\section{References}

[1] Devassy R, Golpalakrishnan S, Torres-de la Roche LA, Verhoeven H, De Wilde MS, De Wilde RL. The missing intrauterine device. Int J Reprod Contracept Obstet Gynaecol $2016 ; 5: 3587-9$.

[2] Dinwoke VO, Okafor CI, Eke A. Intrauterine contraceptive device acceptor in Nnamdi Azikiwe University Teaching Hospital, Nnewi, Southeastern Nigeria: A 5- year review. Trop J Med Res 2015; 18:68-73.

[3] Abasiattai AM, Bassey EA, Udoma EJ. Profile of Intrauterine Contraceptive Device acceptors at the University of Uyo Teaching Hospital, Uyo, Nigeria. Ann Afr Med 2008; 7 (1): 15.

[4] Finer LB, Henshaw SK. Disparities in rates of unintended pregnancy in the United States, 1994 and 2001. Perspect Sex Reprod Health 2006; 38:90-96.

[5] Dinwoke VO, Okafor CI, Eke A. Intrauterine contraceptive device acceptors in Nnamdi Azikiwe University Teaching Hospital, Nnewi, Southeastern Nigeria: Trop J Med Res 2015; 18:68-73.

[6] Igwe NM, Intrauterine contraceptive device use in Abakaliki, Southeast Nigeria: A 5-year review. Trop J Med Res 2016; 19:138-43.

[7] Ezegwui HU, Ikeako LC, Egbuji C. Missing Intrauterine Contraceptive Device among Clients in Enugu. Niger J Surg 2011; 17(2):60-63.

[8] Adewale FB, Ashimi A. Missing intrauterine contraceptive device string. Diagnosis and management at Federal Medical Centre, Bida Northcentral Nigeria. Trop J Obstet Gynaecol 2018; 35:298-303.

[9] Elahi N, Koukab H. Diagnosis and management of lost intrauterine contraceptive device. JPMA 2002; 52: 18.

[10] Eke N, Okpani AO. Extra uterine translocated contraceptive device: A presentation of five cases and revisit of enigmatic issue of iatrogenic perforation and migration. Afr $J$ Reprod Health 2003; 7 (3):117.

[11] Sunder Goyal, Snigdha Goyal. Displaced intrauterine device: A retrospective study. JMR 2016; 2(2): 41-43.

[12] Al-Inany H. Current state of intrauterine contraceptive device. Mid East Fertil Soc J 2007; 12 (1)

[13] Jimoh AAG, Balogun OR. Missing IUD Strings: diagnosis and management at Ilorin. Niger J Med 2004; 13(2):118-123.

[14] Hardman J, . Weiss, B D, Intrauterine Devices: An Update. Am Fam Physician. 2014; 89(6):445-450.

[15] Rahman GA, Yusuf IF. Asymptomatic missing Intrauterine Contraceptive Device found incidentally at laparotomy. JPMA 2009; 59 (4):255-256.

[16] Whitaker AK, Chen BA. Society of Family Planning Guidelines: Postpartum insertion of intrauterine devices. Contraception 97 (2018) 2-13.

[17] Olatinwo AWO, Anate M, Balogun OR, Alao MO. Intrauterine Contraceptive Device: Socio-demographic characteristics of acceptors, acceptability and effectiveness in Teaching Hospital in Nigeria. Niger J Med 2001; 10:14-17.

[18] Singhal SR, Marwah DS, Paul A, Singhal SK. Missed Intrauterine Contraceptive Device: A Rare indication for Appendectomy Case Report with Review Literature. East and Central Afr J Surg 2010; 15 (2):156-158.

[19] Essiet A, Etuk SJ, Bassey DE. Migrant IUD with stone formation in the urinary bladder: Report of a case and review literature. Niger J Surg 2004; 10 (1): 21- 23. 
[20] Majid S. Complication of IUCD. J Postgrad Med Inst 1994; 8: 41-43.

[21] Ikechebelu JI, Mbamara SU. Laparoscopic retrieval of perforated intrauterine device. Niger J Clin Pract b2008; 11:394-5. [PUBMED] [Full text].

[22] Deshmukh S, Ghanouni P, Jeffrey RD. Early Sonographic diagnosis of intrauterine device migration to the adnexa. $J$ Clin Ultrasound 2009; 37 (7): 414-416.

[23] Ibitoye BO, Aremu AA, Onuwaje MA, Ayoola OO. What is the fate of missing intrauterine contraceptive device? Trop Doct 2009; 39:221-223.

[24] Gardyszewska A, Niewiadomska KM, Szymanska B, Roszkowski P, Czajkowski K. Extrauterine mislocated IUCD. Ginekol Pol 2009; 80(12):942-945.

[25] Burkman RT, Brzezinski A. Contraception and Family Planning. In: DeCherney AH, Nathan L, Laufer N, Roman AS (eds). Current Diagnosis and Treatment: Obstetrics and Gynecology. 11 ed. USA: McGraw-Hill; 2013.p. 928-47. 